\title{
Characterization of Hepatocellular Carcinoma Using CT Intensity and K-means
}

\author{
Mohamed E. M. Garelnabi ${ }^{1}$, Mohammed A. Ali Omer ${ }^{1,2}$, Samia A. Fathelrahman ${ }^{3}$ and Albosairi T. Ahmed ${ }^{3}$ \\ ${ }^{1}$ Collage of Medical Radiologic Science, Sudan University of Science and Technology, Khartoum, Sudan \\ ${ }^{2}$ Collage of Applied Medical Science, Department of Radiologic Technology, Qassim University, Buraidah - KSA \\ ${ }^{3}$ College of Applied Medical Sciences, Department of Radiological sciences, Najran University, Najran, KSA
}

\begin{abstract}
The aim of this study was to characterize the hepatocellular carcinoma HCC CT intensity relative to normal liver tissue and other abdominal organs kidney, pancreas and stomach. The method used was the texture analysis which is depends on the collection of CT Number in Hounsfield Unit as excerpted from the k-means technique and the CT system used was tri-phases multidetector computerized tomography MDCT. The analyzed data showed that: the detected mean size of HCC lesions was $11.2 \pm 5.3 \mathrm{~cm}^{2}$. And the mean intensity in $\mathrm{HU}$ of the selected abdominal classes i.e. HCC, liver, kidney, spleen and stomach were $(111,146,137),(128,172.1$, 158), (172, 221, 207.6), (142, 188, 174), (151, 196, 182.7) during plain, arterial and venous phases respectively. While the ultimate golden scored was the intensity\% of HCC relative to normal liver, kidney, spleen and stomach through the different imaging phases (plain, arterial and venous), were: $1 \%, 26 \%, 83 \%, 42 \%$ and $80 \%$ respectively.
\end{abstract}

Keywords: Hepatic, Carcinoma, Texture, Analysis, K-means

\section{Introduction}

Liver as a vital organ could be involved by several serious diseases. One distinct types are tumors which can be benign or malignant. The benign tumors of the liver seen most frequently include cavernous hemangioma, liver cell adenomas, and focal nodular hyperplasia $(\mathrm{FNH})$, while the frequently seen malignant tumors are hepatocellular carcinoma (HCC), intrahepatic cholangiocarcinoma, Bile duct cystadenocarcinoma, and hepatoblastoma [1]. HCC is the third leading cause of death in the world, with annual mortality of more than 500,000 worldwide [2].

Although the main causative factor often is identified, however the common etiological factors stated by scholars are liver cirrhosis, association with hepatitis B virus infection, hepatitis $\mathrm{C}$ virus, alcoholic liver disease, nonalcoholic steatohepatitis, and intake of aflatoxincontaminated food, diabetes, and obesity, and in addition to the geographical factors [3].

The common diagnostic modalities are triple-phase helical CT and triple-phase dynamic contrast enhanced magnetic resonance imaging (MRI) [4, 5]. The significant mark of HCC during CT scan or MRI is the presence of arterial enhancement followed by delayed hypointensity of the tumor in the portal venous and delayed phases, i.e. washout [6]. Such marks depend on the fact that: HCC derives its blood supply predominantly from the hepatic artery, whereas the remainders of normal parenchyma tissues of liver receive via both arterial and portal blood, hence such hemodynamic features during imaging i.e. (arterial hypervascularity and washout in the venous phase) could be utilized successfully in diagnosis of HCC by multi-detector computerized tomography MDCT [7, 8], which in turns leads to an increased enhancement (low density) of the tumor relative to the surrounding liver parenchyma during the hepatic arterial phase as shown by the study introduced by Yau et al, [9].

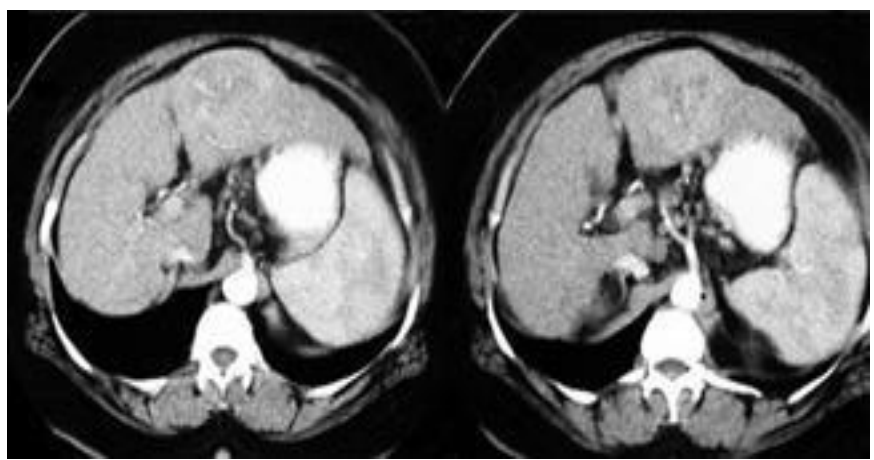

Figure 1: shows the CT scan in the hepatic arterial phase of contrast enhancement showing neovascularity in a lowdensity hepatic mass [9].

However, a variety of entities structures such as dysplastic nodules [10], confluent hepatic fibrosis [11], non-tumors arterioportal shunts [12] and haemangioma [13] can also manifested with increased arterial enhancement and thus mimic HCC, particularly if they were smaller than $2 \mathrm{~cm}$ in diameter; whereas tumor washout (No contrast saturation and No blood phase), i.e. hypoattenuation relative to the adjacent hepatic parenchyma during the hepatic venous or delayed phase, has been recognized as a strong predictor of HCC [14]. This sign has been included, along with the presence of hypervascularity, in the latest American Association for the Study of Liver Diseases (AASLD) guidelines for the diagnosis of HCC at multiphase by MDCT, MRI or contrast-enhanced ultrasonography [7]. Despite the great success in diagnosis of HCC the challenge persists to diagnose small hepatocellular nodules in the cirrhotic liver [15], also the visual inspection and diagnosis of CT scans could not be sufficient for proper image interpretation even for experienced radiologists which in many cases depend on 


\section{International Journal of Science and Research (IJSR) \\ ISSN (Online): 2319-7064}

Index Copernicus Value (2013): 6.14 | Impact Factor (2014): 5.611

a team of radiologists and mostly rely on the invasive procedure like needle biopsy or even surgery. Therefore further research to layout confidence and significant diagnostic technique is in needful.

The worth to be introduced here and will be the aim of this topic is the computer-aided image processing methods taking unique name as texture analysis which utilizes effective classification algorithms to quantify, qualify and extracting the information not normally detected by the human eye. This technique could reduce or even eliminate the necessity of performing the invasive techniques [16, 17]. And to overcome the shortness of using invasive technique and raising the accuracy of Computerized Texture Analysis, different valuable parameters have been considered for accurate qualitative characterization of hepatic diseases such as: texture features, grey scale, fractal dimension estimators or shape descriptors, combined with a classifier [18-19]. Therefore the main objective of this study was to characterize and identify HCC using classification technique depending on the disparity of grey level in case of plain, arterial and venous phases in CT images.

\section{Materials and method}

The study consisted of 200 patients with HCC male and female who are presented for abdominal CT for liver. An abdominal tri-phase multidetector helical CT system used to carry out the required images and the data as intensities in Hounsfield Unit (HU) for the HCC zone; normal liver, spleen, kidney and stomach were collected and interpreted by different radiologists for 50 patients at first and were selected as training set (tri-phase) where a window of $3 \times 3$ pixel was selected to extract the mean intensity per region of interest ROI which included: HCC, normal liver, Kidney, spleen and stomach. The selected data were used as classification center to classify the rest of the data for the 150 patients using kmeans technique for texture analysis discussed by MacQueen, [20]. Then a classification map were generated which included 5 classes within the ROI. The boundaries of HCC class in the classification map were used to delineate the outline of the HCC tumor on the original image.

\section{Results}

The following are the results related to the mean intensity in $\mathrm{HU}$ of the selected abdominal classes on CT for plain, arterial and venous phase, plain CT image for liver and relative abdominal adjacent organs and the enhanced contrast CT image shows the hypo-dense of HCC, hemodynamic phases and the relative intensities in $\mathrm{U}$ for $\mathrm{HCC}$ and others organs and the $\mathrm{HCC}$ intensity in $\mathrm{HU} \%$ relative to plain normal liver intensity and other organs.

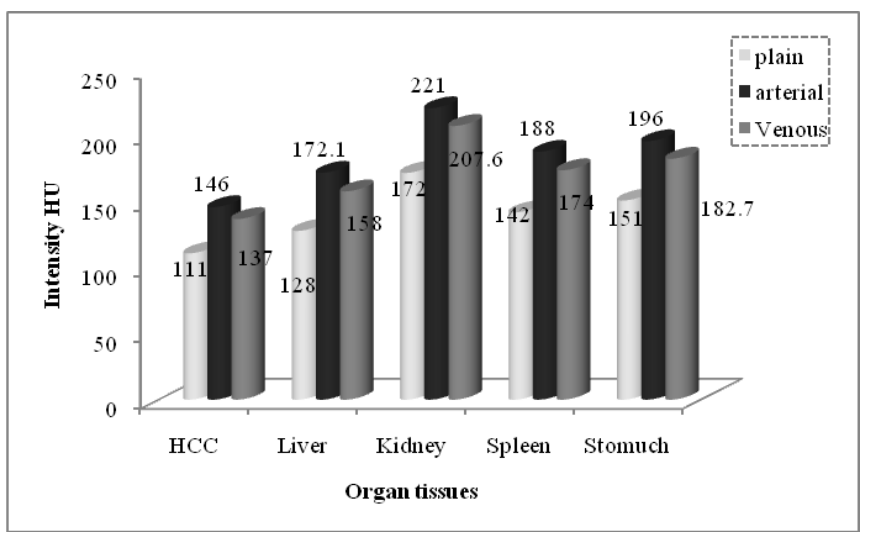

Figure 2: shows the mean intensity in HU of the selected abdominal classes on CT for plain, arterial and venous phase.
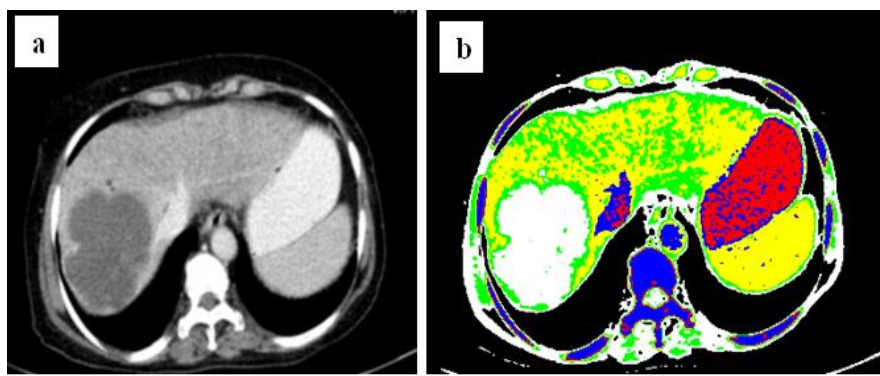

Figure 3: shows (a) the plain $\mathrm{CT}$ image for liver and relative abdominal adjacent organs and (b) the enhanced contrast CT image show the hypo-dense of HCC.

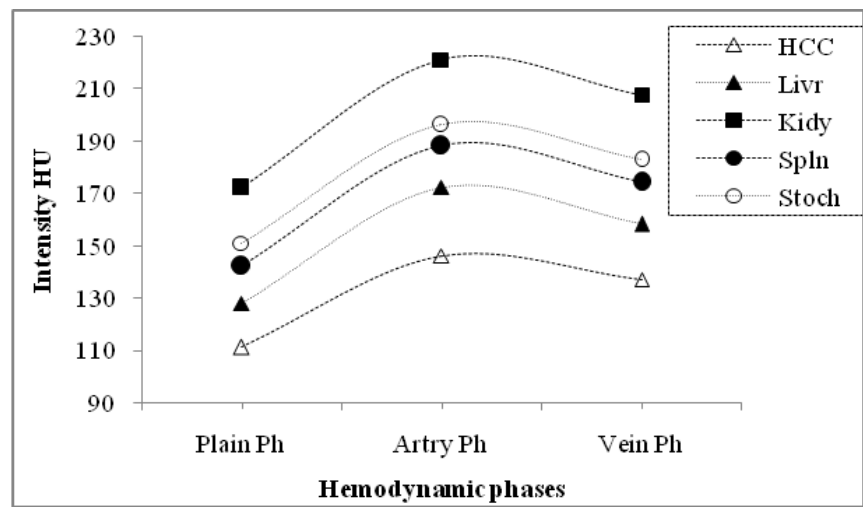

Figure 4: shows the hemodynamic phases and the relative intensities in $\mathrm{U}$ for $\mathrm{HCC}$ and others organs

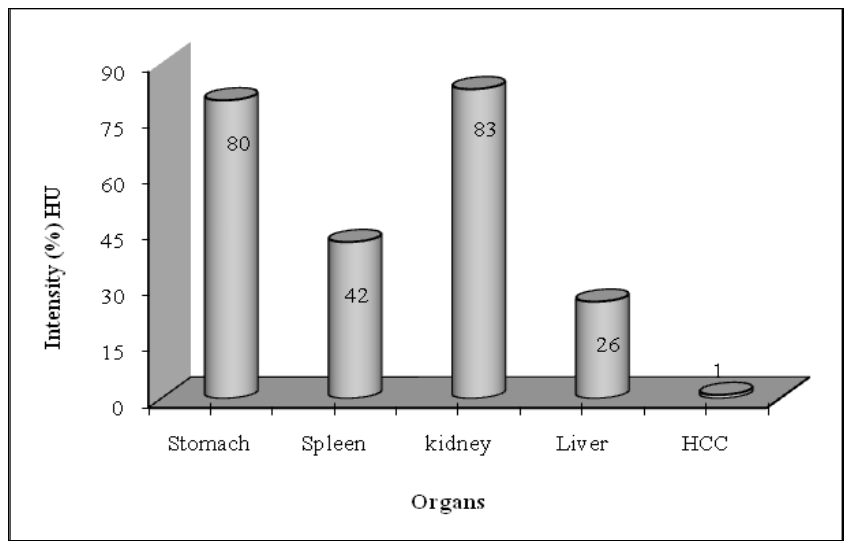

Figure 5: shows the HCC intensity in HU\% relative to plain normal liver intensity and other organs 


\section{International Journal of Science and Research (IJSR) \\ ISSN (Online): 2319-7064}

Index Copernicus Value (2013): 6.14 | Impact Factor (2014): 5.611

\section{Discussion and Analysis}

The mean size of HCC lesions detected during tri-phases of MDCT scan was $11.2 \pm 5.3 \mathrm{~cm}^{2}$ and the mean intensity in HU of the selected abdominal classes i.e. HCC, liver, kidney, spleen and stomach were $(111,146,137),(128,172.1,158)$, $(172,221,207.6),(142,188,174),(151,196,182.7)$ for plain, arterial and venous respectively as shown in Figure (2). The analysis of HCC, liver and other abdominal classes (kidney spleen and stomach) over the different imaging phases (plain, arterial, and venous) showed that, on the precontrast scan (plain) all HCC lesions were either iso-dense or hypo-dense i.e. giving mean intensity (111 HU) which is lower than the other organs and relative to surrounding liver parenchyma; and during the arterial phase $\mathrm{HCC}$ intensity value reached the maximum enhancement with mean intensity of (146 HU), but it is still lower than the surrounding normal liver parenchyma, therefore the tumor appear as hypo-attenuating as shown in Figure $(3,4)$, while during the venous phase the intensity of the tumor were decreased and clearly washout as detected with mean intensity of $(137 \mathrm{HU})$. In contrast the intensity of surrounding normal liver tissue were increased during the hepatic arterial phase showing the plateau at $(172.1 \mathrm{HU})$ and decreased to (158 HU) in venous phase as shown in Figure (4), such phenomena has been ascribed to intra-lesions enhancement of the contrast medium during the arterial phase [21,22] which in turn related to the differences in blood supply.

HCCs receive blood primarily from the hepatic arteries and therefore tend to enhance more avidly than background normal liver during arterial phase imaging, as the normal liver receives approximately $25 \%$ of its blood supply from the hepatic artery and $75 \%$ from the portal vein during the portal venous phase of contrast enhancement. The liver continues to enhance, and the lack of portal venous blood supply to HCCs results in the characteristic washout in the portal venous phase and especially in the delayed phase, in addition, the liver parenchyma is often fibrotic in patients with HCC, hence all will be as factors contribute to the appeaance of hypodense of HCCs in the portal venous and delayed phases [23].

The detected large size of HCC tumors $\left(11.2 \mathrm{~cm}^{2}\right)$ are most likely associated with necrotic tissues, therefore, blood supply will be poor during the arterial phase; which also contributes to the hypodense appearance of HCCs in the arterial phase.

Similarly in plain phase HCC also associated with hypodense appearance, which means that the component of HCC consist of component softer than the normal tissues which is necrotic cell with fluid like pus cells and dead tissues. In comparison with previous study; the small size $\mathrm{HCC}$ lesions $<2 \mathrm{~cm}^{2}$ mostly appear as hyper-dense in the arterial and venous phase because the blood supply was so good enough with minimum necrotic tissues. In such realm Monzawa et al. [24], found that some HCCs, especially small or well-differentiated lesions, may not be hyper-enhancing on arterial phase images, and only $58 \%$ of HCCs $<2 \mathrm{~cm}$ were hyper-vascular on the arterial phase. Conversely, a minority of hyper- vascular HCCs may not exhibit washout on portal venous or delayed phase image; as has been stated by Lee et al [25].

In the current results, there was a significant difference between the intensity value of $\mathrm{HCC}$ relative to plain normal liver, and other abdominal classes (kidney, spleen and stomach) through the different imaging phases, that gives: $1 \%, 26 \%, 83 \%, 42 \%$ and $80 \%$ for HCC, normal Liver, kidney, spleen and stomach respectively as shown in Figure (5), which can help in delineated the outline and counter of the HCC from other abdominal organs.

\section{Conclusion}

Texture analysis depending on the relative attenuation coefficient of tissues i.e. the CT No in HU could serves the diagnostic field and overcoming the visual diagnosis that comes with different interpretation and also would have promising future to avoid invasive technique if the base line for individual tissues being determined and algorithmic aided computer have been applied.

\section{References}

[1] Dushyant V. Sahani, Sanjeeva P. Kalva, (2004). "Imaging the Liver" The Oncologist, vol. 9. P: 385-397.

[2] Parkin DM, Bray F, Ferlay J, Pisani P. (2005). Global cancer statistics, CA Cancer J Clin. Vol. 55, P: 74-108.

[3] Sanyal AJ, Yoon SK, Lencioni R. (2010). The etiology of hepatocellular carcinoma and consequences for treatment. Oncologist; 15, Suppl. 4, P: 14-22. doi: 10.1634/theoncologist.2010-S4-14.

[4] Choi D, Kim SH, Lim JH, (2001). Detection of hepatocellular carcinoma: combined T2-weighted and dynamic gadolinium-enhanced MRI versus combined CT during arterial portography and CT hepatic arteriography. J Comput Assist Tomogr vol. 25, P: 777 785.

[5] Arguedas MR, Chen VK, Eloubeidi MA, et al. (2003). Screening for hepatocellular carcinoma in patients with hepatitis C cirrhosis: a cost-utility analysis. Am J Gastroenterol vol. 98, P: 679-690.

[6] Marrero JA, Hussain HK, Nghiem HV, et al. (2005). Improving the prediction of hepatocellular carcinoma in cirrhotic patients with an arteriallyenhancing liver mass Liver Transpl vol. 11, P: 281-289.

[7] Bruix J, Sherman M. (2005). Management of hepatocellular carcinoma. Hepatology vol. 42, P: 12081236.

[8] Baron RL, Oliver JH, Dodd GD, Nalesnik M, Holbert BL, Carr B. (1996). Hepatocellular carcinoma: evaluation with biphasic, contrast-enhanced helical CT. Radiology vol. 199, P: 505-511.

[9] Yau T, Chan P, Epstein R, Poon RT. (2009). Management of advanced hepatocellular carcinoma in the era of targeted therapy. Liver Int. vol. 29(1), P: 107. [Medline].

[10] Krinsky GA, Theise ND, Rofsky NM, Mizrachi H, Tepperman LW, Weinreb JC. (1998). Dysplastic nodules in cirrhotic liver: arterial phase enhancement at 


\section{International Journal of Science and Research (IJSR) \\ ISSN (Online): 2319-7064}

Index Copernicus Value (2013): 6.14 | Impact Factor (2014): 5.611

CT and MR imaging - a case report. Radiology vol. 209, P: 461-464.

[11] Ohtomo K, Baron RL, Dodd G, Federle MP, Miller WJ, Campbell WL, et al. (1993). Confluent hepatic fibrosis in advanced cirrhosis: appearance at CT. Radiology vol. 188, P: 31-35.

[12] Kim TK, Choi BI, Han JK, Chung JW, Park JH, Han MC. (1998). Nontumorous arterioportal shunt mimicking hypervascular tumor in cirrhotic liver: twophase spiral CT findings. Radiology vol. 208, P: 597603.

[13] Brancatelli G, Federle MP, Blachar A, Grazioli L. (2001). Hemangioma in the cirrhotic liver: diagnosis and natural history. Radiology vol. 219, P: 69-74.

[14] Carlos RC, Kim HM, Hussain HK, Francis IR, Nghiem HV, Fendrick AM. (2003). Developing a prediction rule to assess hepatic malignancy in patients with cirrhosis. AJR Am J Roentgenol vol. 180, P: 893-900.

[15] Byung Ihn Choi , Jeong Min Lee. (2010). Imaging diagnosis and staging of hepatocellular carcinoma. J. Hepatobiliary Pancreat Sci vol. 17, P: 369-373.

[16] Bruno A., Collorec R., Bezy-Wendling J., Reuze P., Rolland Y.: (1997). Texture analysis in medical imaging, In: Roux C., Coatrieux J. L. (Eds.): Contemporary Perspectives in Three-dimensional Biomedical Imaging, IOS Press, P: 133-164.

[17] H.M. Taylor, P.R. Ros, . (1998). Hepatic Imaging: An Overview. Radiologic Clinics of North America, vol. 36 (2).

[18] Y.N. Sun, M.H. Horng, X.Z. Lin, and J.Y. Wang. (1996) .Ultrasonic Image Analysis for Live Diagnosis,. IEEE Engineering in Medicine and Biology, vol. 11-12, P: 93-101.

[19] E.L. Chen, P-C. Chung, C.L. Chen, H.M. Tsa, and C.I. Chang. (1998). An Automatic Diagnostic System for CT Liver Image Classification,. IEEE Transactions on Biomedical Engineering, vol. 45(6), P: 783-794.

[20] MacQueen J. B. (1967): "Some Methods for classification and Analysis of Multivariate Observations, Proceedings of 5-th Berkeley Symposium on Mathematical Statistics and Probability", Berkeley, University of California Press, 1:281-297.

[21] Loyer EM, Chin HC, DuBrow RA, David CL, Eftekhari F, Charnsangavej C. (1999). Hepatocellular carcinoma and intrahepatic peripheral cholangiocarcinoma: enhancement patterns with quadruple phase helical CT a comparative study. Radiology vol. 212, P: 866-875.

[22] Kim T, Murakami T, Takahashi S, Tsuda K, Tomoda K, Narumi Y, et al. (1999). Optimal phases of dynamic CT for detecting hepatocellular carcinoma: evaluation of unenhanced and triple-phase images. Abdom Imaging vol. 24, P: 473-480.

[23] Kamaya A, Maturen KE, Tye GA, Liu YI, Parti NN, Desser TS. (2009). Hypervascular liver lesions. Semin Ultrasound CT MR vol. 30, P: 387-407.

[24] Monzawa S, Ichikawa T, Nakajima H, Kitanaka Y, Omata K, Araki T. (2007). Dynamic CT for detecting small hepatocellular carcinoma: usefulness of delayed phase imaging. AJR vol. 188, P: 147-153.

[25] Lee J., Lee WJ., Lim HK., Lim JH., Choi N., Park M., KimS W., \& Park CK. (2008). Early hepatocellular carcinoma: three-phase helical CT features of 16 patients. Korean J. Radiology, Vol. 9, P: 325-332, ISSN 1229-6929.

\section{Author Profile}

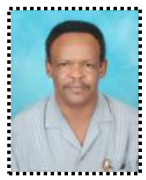

Mohamed Elfadil M. Gar-elnabi: received the B. Sc. in Radiotherapy and Nuclear Medicine, and M.Sc. degrees in Medical Physics from Sudan University of Science and Technology in 1995 and 2001 respectively. He has been working as medical physicist and radiation technologist at Radiation and Isotopes Center of Khartoum as well as a lecturer at College of Medical Radiologic Science - Sudan University of Science and Technology. He awarded a PhD. degree from Natal University South Africa 2007 in Medical physics, and now working as a lecturer (Associate Prof.) at Sudan University of Science and Technology-KhartoumSudan.

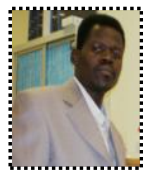

Mohammed Ahmed A. Omer: received the B. Sc. -1. in Radiotherapy and Nuclear Medicine, B. Sc.-2 in Medical Equipments Technology and M.Sc. degrees in Medical Physics from Sudan University of Science and Technology in 1995, 1998 and 2001, respectively.

He has been working as medical and radiation technologist at Radiation and Isotopes Center of Khartoum as well as a lecturer at College of Medical Radiologic Science, Sudan University of Science and Technology. He received a $\mathrm{PhD}$. degree from University Putra Malaysia - 2007 in Medical physics-Applied Radiation, and now working as a lecturer (Associate Prof.) at Qassim University-Buraidah-KSA.

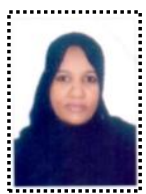

Samia A. Fathelrahman: Awarded B. Sc. and M. Sc. Degree in diagnostic radiology in 1995 and 2005 respectively from Sudan University of science and technology. She has been working as radiology specialist at Ibn Sinaa Hospital (1996-2004), Lecturer at Sebai Institute for Medical training in Almadina branch-KSA (2005-2009) and as a lecturer at Najran University, college of applied medical sciences-department of radiological Sciences from 2009 up to date. And she is a PhD candidate in Sudan University of Science and Technology in the same field.

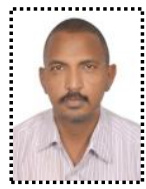

Albosairi T. Ahmed: Awarded B. Sc. in diagnostic radiology 1995 and $M$. Sc. Degree in diagnostic ultrasound in 2007 from Sudan University of science and technology. He has been working as radiology specialist in many Sudanese clinics, and then working at Saudi Arabia-ministry of health during 2000-2008, then joined Najran University staff from 2008 up to date. And now he is a $\mathrm{PhD}$. candidate in the same field. 